\title{
Small scale distribution patterns and vertical migration of North Sea herring larvae (Clupea harengus, Teleostei: Clupeidea) in relation to abiotic and biotic factors
}

\author{
HOLGER HASLOB $^{1}$, NORBERT ROHLF ${ }^{2}$ and DIETRICH SCHNACK ${ }^{1}$ \\ ${ }^{1}$ IFM-GEOMAR, Leibniz Institute of Marine Sciences, Düsternbrooker Weg 20, 24105 Kiel, Germany. \\ E-mail: hhaslob@ifm-geomar.de \\ ${ }^{2}$ Johann Heinrich von Thünen Institute of Sea Fisheries, Palmaille 9, 22767 Hamburg, Germany.
}

\begin{abstract}
SUMMARY: The distribution of herring larvae in relation to environmental conditions and the occurrence of possible prey and predator organisms was studied during a 4-day period on a permanent station in the northern North Sea in September 1999. The vertical distribution of herring larvae was sampled in $20-\mathrm{m}$ intervals by means of a multiple-closing net. To resolve the small-scale patchiness of herring larvae and planktonic prey and predator organisms, a towed in-situ video system was used, the Ichthyoplankton Recorder. A diel vertical migration of herring larvae was observed with different intensities depending on their body length. Small larvae $(<10 \mathrm{~mm})$ were concentrated in the upper water layers during daytime and were distributed more homogenously during night time. Large larvae $(>16 \mathrm{~mm})$ showed the highest abundances in the upper water layers during the day and were concentrated in deeper water layers during the night. The presented results appear to be relevant for individual-based modelling of the fate of larval herring populations.
\end{abstract}

Keywords: Clupea harengus, vertical distribution, larval behaviour.

RESUMEN: LA DISTRIBUCIÓN A PEQUEÑA ESCALA Y LA MIGRACIÓN VERTICAL DE LARVAS DE ARENQUE DEL MAR DEL NoRTE (CLUPEA haRENGUS, TELEOSTEI: ClupeideA) EN RELACIÓN CON FACTORES ABIÓticos Y Bióticos. - Se han estudiado la distribución de las larvas de arenque en relación a las condiciones ambientales y la incidencia de posibles presas y organismos depredadores a lo largo de un periodo de 4 días en una estación permanente situada en el Mar del Norte en septiembre de 1999. La distribución vertical de las larvas de arenque fue muestreada en intervalos de $20 \mathrm{~m}$ mediante una red de apertura múltiple (multiple opening/closing net). Para determinar a pequeña escala la heterogeneidad en la distribución de las larvas de arenque, así como de las presas y depredadores planctónicos, se utilizó un sistema de vídeo in-situ (The Ichthyoplankton Recorder). Se observó una migración vertical nictimeral con diferentes intensidades dependiendo de la longitud corporal de las larvas. Las larvas pequeñas $(<10 \mathrm{~mm})$ se concentraban en las capas superiores de la columna de agua durante el día y se distribuían más homogéneamente durante la noche. Las larvas más grandes (>16 mm) mostraban su mayor abundancia en las capas superiores de la columna de agua durante el día y se concentraban en capas de agua más profundas durante la noche. Los resultados presentados en este trabajo pueden ser relevantes para la modelización (individual based modeling) del destino de las poblaciones de larvas del arenque.

Palabras clave: Clupea harengus, distribución vertical, comportamiento de las larvas.

\section{INTRODUCTION}

The horizontal and vertical distribution patterns of fish larvae in relation to environmental parame- ters are of interest to obtain a better understanding of the processes driving the survival of early life stages in marine fish stocks. In the vertical plane, current speed is of a magnitude that allows fish larvae and 
other planktonic organisms to conduct vertical migrations through the water column (Munk et al., 1989). As the intensity of currents can vary along the water column, the vertical distribution may affect the horizontal dispersal of fish larvae and thus the drift of larval cohorts to their nursery areas. Therefore, information on the behaviour of fish larvae and the resulting vertical distribution is important for the parameterisation of drift models. In recent years, a number of drift models have been used to provide insight into the fate of cohorts of fish larvae (Bartsch et al., 1989; Hinckley et al., 2001; Hinrichsen et al., 2005). From the major spawning grounds of North Sea herring, located to the east coast of Great Britain, the herring larvae drift towards their nursery areas located in the German Bight (Corten, 1986). The detailed data on the vertical distribution of herring larvae obtained within the present study could serve as input data for a model to predict this transport. In combination with environmental data, such a model could provide information about the fate and survival probability of herring larvae populations. This knowledge is important to enhance the understanding of North Sea herring recruitment processes.

Several studies dealing with the vertical distribution pattern of herring larvae have been conducted in the past (Wood, 1971; Seliverstov, 1974; Grainger, 1980; Stephenson and Power, 1988; Munk et al., 1989; Heath et al., 1991). Often a diel periodicity in the vertical movement of larvae was detected, but results of these studies showed no uniform picture. High concentrations of herring larvae were found near the surface both during the day (Grainger, 1980; Heath et al., 1991) and at night (Seliverstov, 1974; Sjøblom and Parmanne, 1978). Wood (1971) observed a high concentration of larvae near the surface in overcast weather conditions and at mid-depths with a clear sky. High concentrations of herring larvae in deeper water layers were described by Seliverstov (1974). Other authors found a homogenous distribution along the whole water column (Wood, 1971; Henderson, 1987; Heath, 1988). Heath et al. (1991) examined the vertical distribution of herring larvae of the North Sea autumn spawner stock in the framework of the Autumn Circulation Experiment (ACE 19871988) at 10 different stations in the whole North Sea and found different vertical distribution patterns. The majority of Heath's observations showed that herring larvae stay more in the upper water layer during the day. Several explanations for the vertical migration of herring larvae can be found in the literature, including the influence of tidal currents (Stephenson and Power, 1988), the combination of light and turbulence (Heath et al., 1988), predatorprey relationship (Houde and Bailey, 1989), and dependency on light and food availability (Munk et al., 1989).

The focus of the present study was the vertical distribution pattern of herring larvae in the North Sea, namely the Shetland/Orkney area, which was observed over a period of 4 days. The goal of the study was to detect possible migration movements and to explain these in relation to environmental conditions. In addition to a conventional multipleclosing net, a towed in-situ camera system was employed to explore its possibility of resolving the fine scale distribution patterns of herring larvae in relation to their possible prey and predator organisms.

\section{MATERIALS AND METHODS}

This study was carried out in the Shetland/Orkney area from the RV Heincke on 26 to 30 September 1999 during the spawning season of the North Sea autumn spawning herring. The sampling station (water depth $110 \mathrm{~m}$ ) was located on a permanent station east of the Orkney Islands at $58^{\circ} 35^{\prime}$ North and $01^{\circ} 30^{\prime}$ West. This position at the edge of the herring larval distribution, observed during this survey (Fig. 1), was chosen in order to cover a station with a depth of at least 100

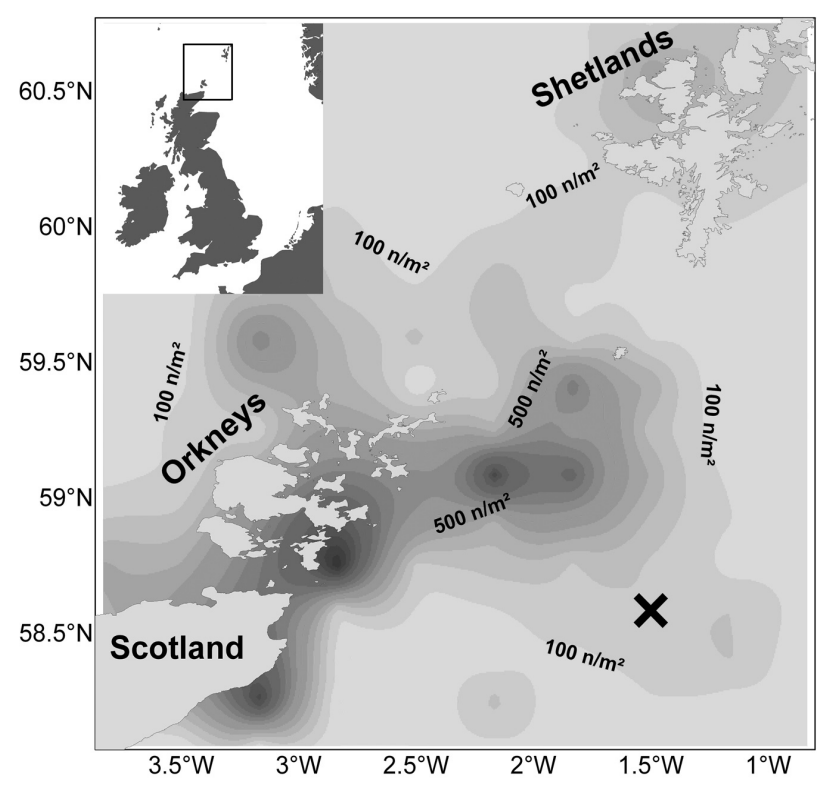

FIG. 1. - Horizontal distribution of herring larvae abundance [numbers $/ \mathrm{m}^{2}$ ] in the investigation area of the Orkney/Shetlands, observed during the International Herring Larvae Survey in September 1999. The position of the permanent station is marked by a black cross. 
$\mathrm{m}$ and to obtain larvae of a broad size range. Sampling to resolve the vertical distribution of herring larvae was conducted with a conventional multiple-closing net equipped with six nets of 335- $\mu \mathrm{m}$ mesh size. In order to investigate the diel migration of herring larvae, hauls with this gear were conducted every $4 \mathrm{~h}$ over a 4-day period. As sunrise and sunset were approximately at 06:00 [UTC] and 17:50 [UTC] respectively during the investigation period, full daylight prevailed during the hauls at 10:00 [UTC] and 14:00 [UTC]. The remaining hauls were conducted in twilight or complete darkness. Due to the technical setup of the gear, the first net covered the whole water column and was thus excluded from the analysis. With the remaining five nets the water column was sampled in 20-m steps. Towing time at each specific depth was $8 \mathrm{~min}$, after which the gear was heaved and a new net was opened to sample the next depth stratum. Towing speed was 5 knots. A flowmeter attached to the gear measured the filtered volume of each net. The samples were fixed in a $4 \%$ buffered formaldehyde fresh water solution immediately after the haul. All herring larvae and other fish larvae were sorted from the samples in the laboratory using a stereo microscope. The standard length of herring larvae was measured to the lowest millimetre using the ImageJ image analysis software (Rasband, 1997-2008). Damaged larvae were excluded from the length measurements. No correction for shrinkage due to formaldehyde preservation was performed. The numbers of herring larvae were standardised to $\mathrm{n}$ / $\mathrm{m}^{3}$ for each depth stratum and haul. In order to detect possible changes in the behaviour of larvae in different ontogenetic stages, the herring larvae were divided into three size groups: $<10 \mathrm{~mm}, 10-16 \mathrm{~mm}$ and $>16$ $\mathrm{mm}$. These size groups have traditionally been used in the International Herring Larvae Survey for North Sea herring (ICES, 2008; Gröger et al., 2001; Saville, 1978) and have been used by other authors before (e.g. Heath, 1988; Munk et al., 1989), so the results of the present study are well comparable with previous findings. The first size group of small larvae was chosen to reflect the behaviour of yolk-sac larvae and firstfeeding larvae (Heath et al., 1991; Munk et al., 1989). The medium size group contains larvae which have already grown because of successful feeding but are still dependent on a comparatively narrow prey spectrum and restricted in their swimming ability. Thus, the proper food availability is still essential for this group of larvae, and the mortality due to starvation is in general high. The morphological development of the last group of larvae, in particular the formation of fins, is considerably progressed. The spectrum of prey has become broader than for the other groups, and the food availability is in general not as critical as in smaller larvae.

For statistical analyses the mean depth $(Z \mathrm{~cm})$ of the larvae was calculated using the formula for centre of mass:

$$
Z \mathrm{~cm}=\Sigma P_{i} Z_{i}
$$

where $Z_{i}$ is the depth of the $i_{\text {th }}$ sample and $P_{i}$ the proportion of larvae at depth $Z_{i}$ from the sum of larvae per $\mathrm{m}^{3}$ over all depth strata (Fortier and Leggett 1983).

In order to quantify the breadth of the vertical distribution, an aggregation index introduced by Heath et al. (1988) was calculated. An aggregation index of zero is equal to a uniform distribution of larvae, increasing values indicating aggregation of larvae. This index is estimated as the mean deviation from the average density observed for the whole water column with each multinet haul (Heath et al., 1991):

$$
A_{i}=\frac{1}{b} * \sqrt{\sum_{b}^{1}\left(p_{i}-p\right)^{2}},
$$

where $b$ is the water depth of the station and $p$ is the mean proportion of larvae along the whole water column. The parameter $p_{i}$ is the proportion of larvae per 1-m depth interval and was estimated by linear interpolation from the larvae abundance observed for each 20-m depth stratum with the multinet.

As data on mean depth and aggregation index met assumptions of normality and homogeneity of variances, in both cases a two-way ANOVA was performed with size group and daytime as factor variables.

In parallel, the small-scale distribution of herring larvae in relation to possible planktonic prey and predator organisms was investigated with a towed in-situ camera system, the Ichthyoplankton Recorder (IPR). The IPR was developed in the frame of the MAROPTProject (Lenz et al., 1995) at the department of Fishery Biology at the Leibniz Institute of Marine Sciences (IFM-GEOMAR), Kiel Germany. A highly sensitive video system is integrated into the cod end of a Gulf III high speed plankton sampler. A CTD probe and flow sensors are attached to the gear. The system is able to detect fish larvae and other planktonic organisms in the size range of 0.5 to $20 \mathrm{~mm}$. The video signals and environmental data are recorded onboard 
the research vessel. Organisms entering the $20 \mathrm{~cm}$ net opening are concentrated to an entrance area of the measuring channel of $15 \times 15 \mathrm{~mm}$, illuminated by strobed light-emitting diodes (LEDs). The length of the field scanned by the camera is $20 \mathrm{~mm}$. The camera works with a frequency of 50 images per second. The main advantage of the IPR is the fine spatial resolution compared with conventional plankton samplers, allowing a spatial resolution of a few centimetres in both the horizontal and the vertical plane. Due to the lack of suitable software for automated image analysis, the examination of the video tapes was performed manually. Copepods and pteropods were counted as possible prey items (Cohen and Lough, 1983; Fox et al., 1999), and chaetognaths and ctenophores as possible predators (Brewer et al., 1984; Purcell, 1985). For seven IPR recordings taken during the investigation in September 1999, herring larvae and their potential predator organisms were counted for the complete IPR haul. Two hauls were taken during each day, at 07:00 [UTC] during daylight, and 19:00 [UTC] during darkness respectively. In addition, one tape of an investigation conducted on the same permanent station in September 2000 was analysed for the vertical fine-scale distribution of plankton organisms. In this case, potential prey organisms of herring larvae were also counted. The number of these organisms was determined for consecutive time slots of ten seconds of the video tape with a counter. The values of recorded organisms obtained were standardised to numbers per $\mathrm{m}^{3}$. This analysis was restricted to the first $40 \mathrm{~m}$ of the water column, where the majority of herring larvae were recorded. Because the data obtained did not meet the assumptions required for a parametric

26.09.1999

27.09.1999 correlation analysis, a Spearman rank correlation was conducted to test whether a relationship between the abundance of prey or predators and herring larvae could be detected on such a fine scale.

Water temperature and salinity were measured with a CTD on the permanent station every day, once in the morning and once in the evening. Salinity was measured in practical salinity units (psu). Wind speed and daylight intensity were measured continuously with the meteorological equipment of the research vessel, located on a mast $20 \mathrm{~m}$ above the sea surface. In order to test whether a significant relationship existed between the mean depth of herring larvae groups and the two latter variables the non-parametric Spearman rank correlation was applied, as the assumptions for a parametric correlation analysis were not met. The multiple correlation comparisons were adjusted with a sequential Bonferroni technique (Holm, 1979; Rice, 1989).

\section{RESULTS}

\section{Physical parameters}

The hydrographical situation on the permanent station was characterised by a mixed water column, with only minor changes over the 4-day period observed (Fig. 2). The mean salinity at the surface was 35.12 ( $\mathrm{SD} \pm 0.03)$. The mean salinity near the sea bottom was slightly higher at $35.30(\mathrm{SD} \pm 0.01)$. The temperature was on average $12.84^{\circ} \mathrm{C}(\mathrm{SD} \pm 0.1)$ at the surface and $11.37^{\circ} \mathrm{C}(\mathrm{SD} \pm 0.13)$ near the sea bottom, resulting in a mean temperature range of $1.48^{\circ} \mathrm{C}$. During the first

28.09.1999

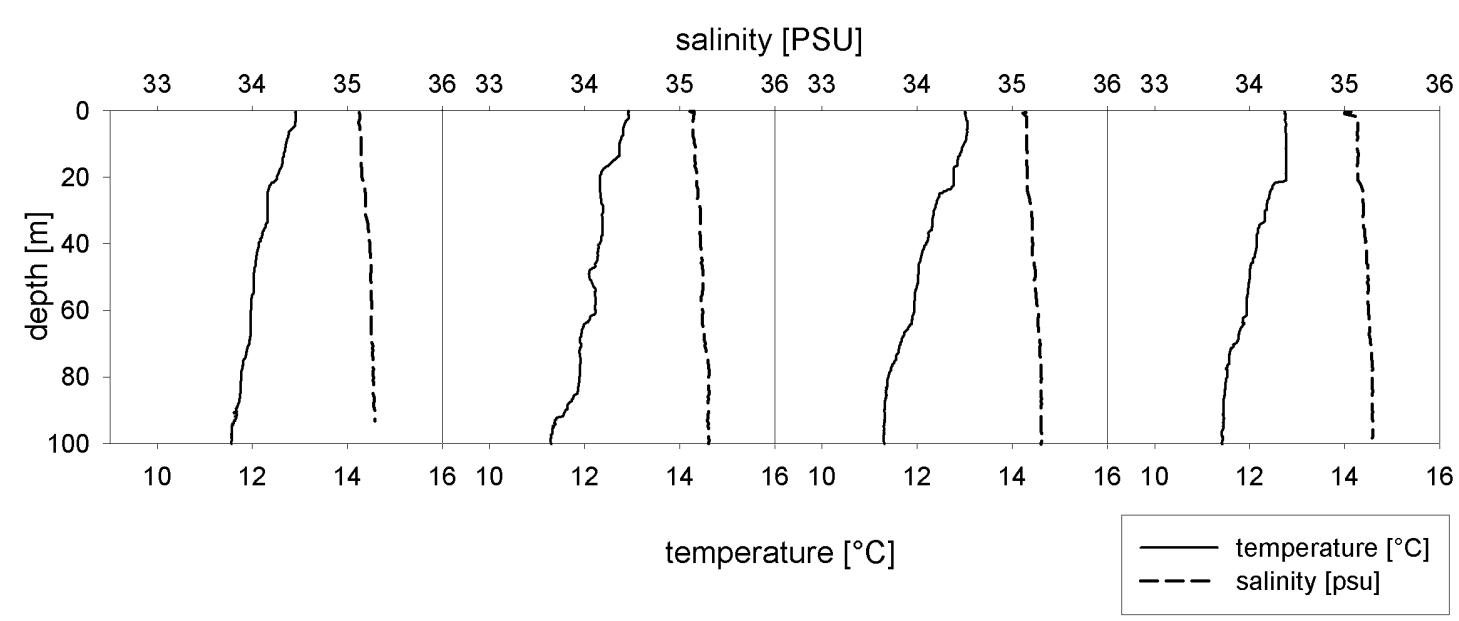

FIG. 2. - Temperature (solid line) and salinity (dashed line) profiles of the permanent station for the investigated period 26.09. - 29.09.1999. Profiles were taken at 19:00 [UTC] each day. 

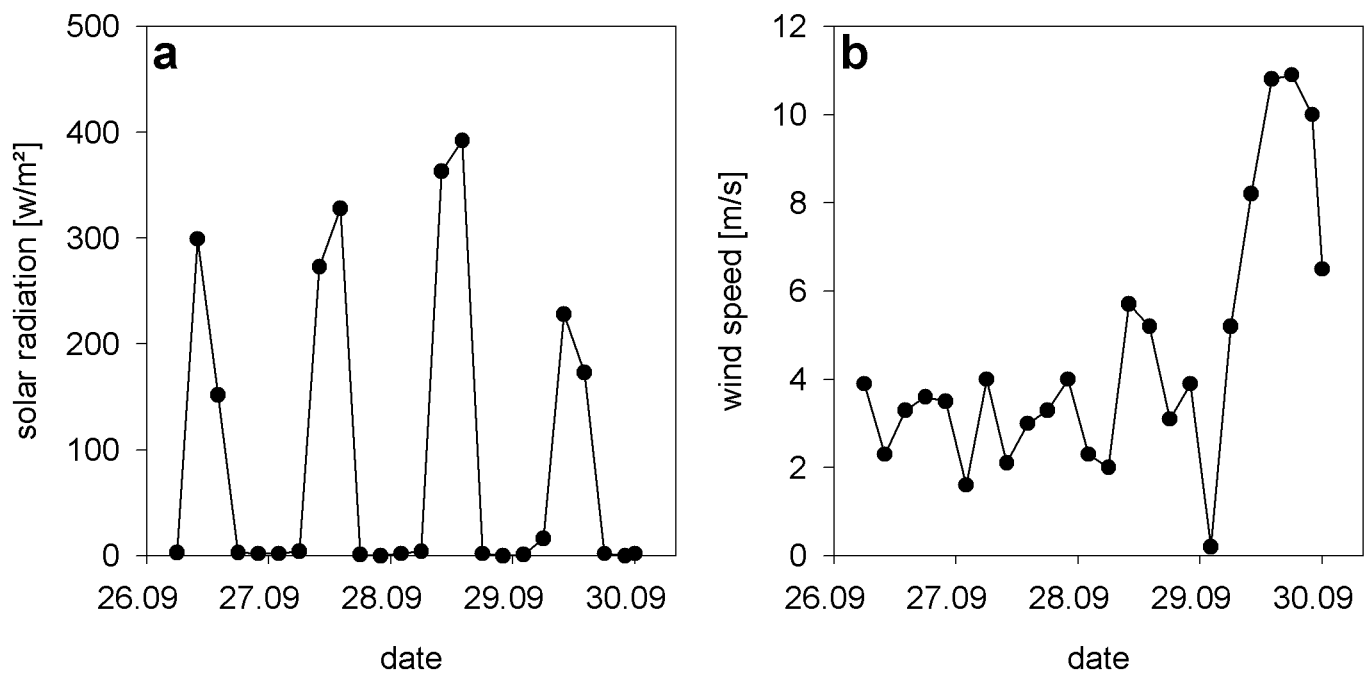

FIG. 3. - Solar radiation (a) and wind speed (b) during the investigation period.

two days of the investigation the solar radiation varied between 150 and $320 \mathrm{~W} / \mathrm{m}^{2}$ and a maximum of 400 $\mathrm{W} / \mathrm{m}^{2}$ was reached on the third day (Fig. 3a). Wind speed ranged between 2 and $4 \mathrm{~m} / \mathrm{s}$, resulting in a calm sea on the first two days (Fig. 3b). It increased slightly on the third day but dropped again in the afternoon of the same day, and reached a minimum of $0.2 \mathrm{~m} / \mathrm{s}$ in the early morning of the fourth day. During the last day wind speed increased and reached a maximum of $10.6 \mathrm{~m} / \mathrm{s}$, resulting in a rough sea during the last three hauls with the multinet.

\section{Multinet hauls}

The total number of herring larvae caught with the multinet was 9244, of which 9020 were measured for standard length. The remaining 224 larvae were damaged and therefore excluded from the length measurements. The larval length ranged from 6 to $25 \mathrm{~mm}$. Of the defined size groups, small larvae contributed $23.3 \%(n=2099)$ of the material, medium-sized larvae $68.9 \%(\mathrm{n}=6212)$, and large larvae $7.9 \%(n=709)$.

Herring larvae were found in all depth strata, but showed a pronounced diel vertical migration within the observed time period (Fig. 4). From the early morning hours (06:00 [UTC]) and during daylight, the larvae were concentrated in the upper $(0-20 \mathrm{~m})$ and middle water layers $(20-40 \mathrm{~m})$, and were rarely found at depths below $60 \mathrm{~m}$. In some cases no larvae at all were caught at $90 \mathrm{~m}$ during daytime. During the night, larvae were more homogenously distributed throughout the water column. This migration pattern was already visible for small larvae $(<10 \mathrm{~mm})$ (Fig. 4a) and was similar for the medium-sized larvae (10 $\mathrm{mm}$ to $15 \mathrm{~mm}$ ) (Fig. 4b). In the large larvae ( $\geq 16 \mathrm{~mm})$, the diel vertical migration was more pronounced than in the other two groups (Fig. 4c). Large larvae were rarely found in upper water layers during the night and only very few larvae were found below $60 \mathrm{~m}$ during the day. The differences in mean depths (Fig. 5a) were statistically significant among the size groups of larvae as well as among daytime periods (Table 2 ). The aggregation index shows increasing values during the day and decreasing values during the night for all three size groups (Fig. 5b). These differences among daytime periods were statistically significant, whereas no significant differences were found among the size groups of larvae for the aggregation parameter (Table 2).

The vertical distribution of larvae was significantly correlated with solar radiation (Table $1)$, with the strongest correlation for large larvae $\left(r_{s}=0.77 ; p<0.05\right)$, while no correlation was found with wind speed.

\section{Ichthyoplankton recorder hauls}

The fine-scale vertical distribution analysis revealed concentrations of 0 to 0.95 herring larvae per $\mathrm{m}^{3}$ and 1-m depth stratum (Fig. 6b). Copepods and pteropods showed much higher numbers, with a maximum of 15 and 37 individuals per $\mathrm{m}^{3}$, respectively (Fig. 6a). Chaetognaths were recorded with a maximum of 0.95 individuals per $\mathrm{m}^{3}$ (Fig. 6c). Ctenophores occurred only in low numbers, up to 0.32 individuals per $\mathrm{m}^{3}$ (Fig. 6c). 


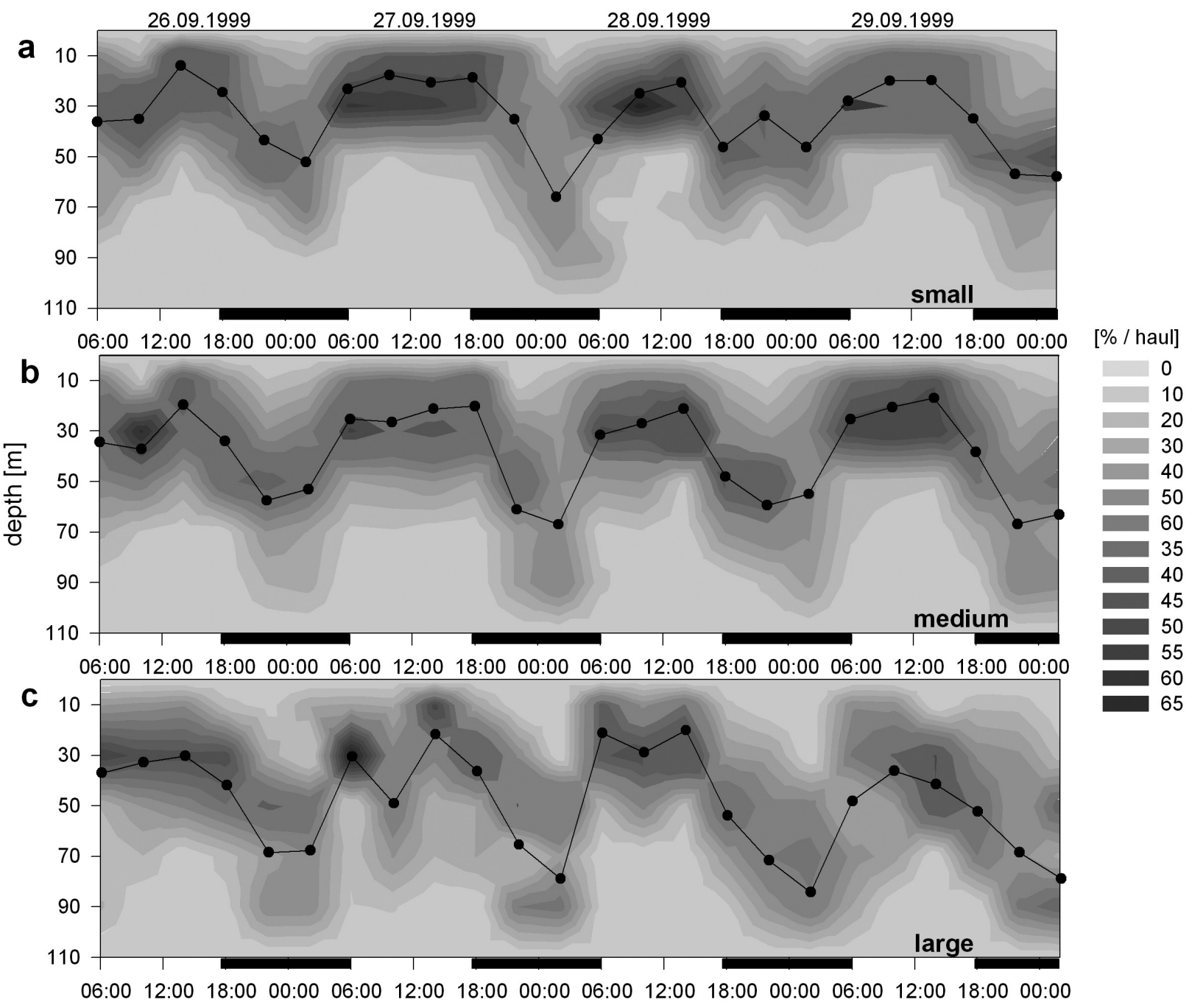

FIG. 4. - Vertical distribution pattern of herring larvae during the investigation period 26-30 September 1999. Contour plots show the percentage of larvae in each depth stratum per haul. Line plots show the mean depth of larvae. Black bars below the x-axis indicate period of darkness. (a) small larvae $\leq 9 \mathrm{~mm}$; (b) medium larvae $10-15 \mathrm{~mm}$; (c) large larvae $\geq 16 \mathrm{~mm}$.
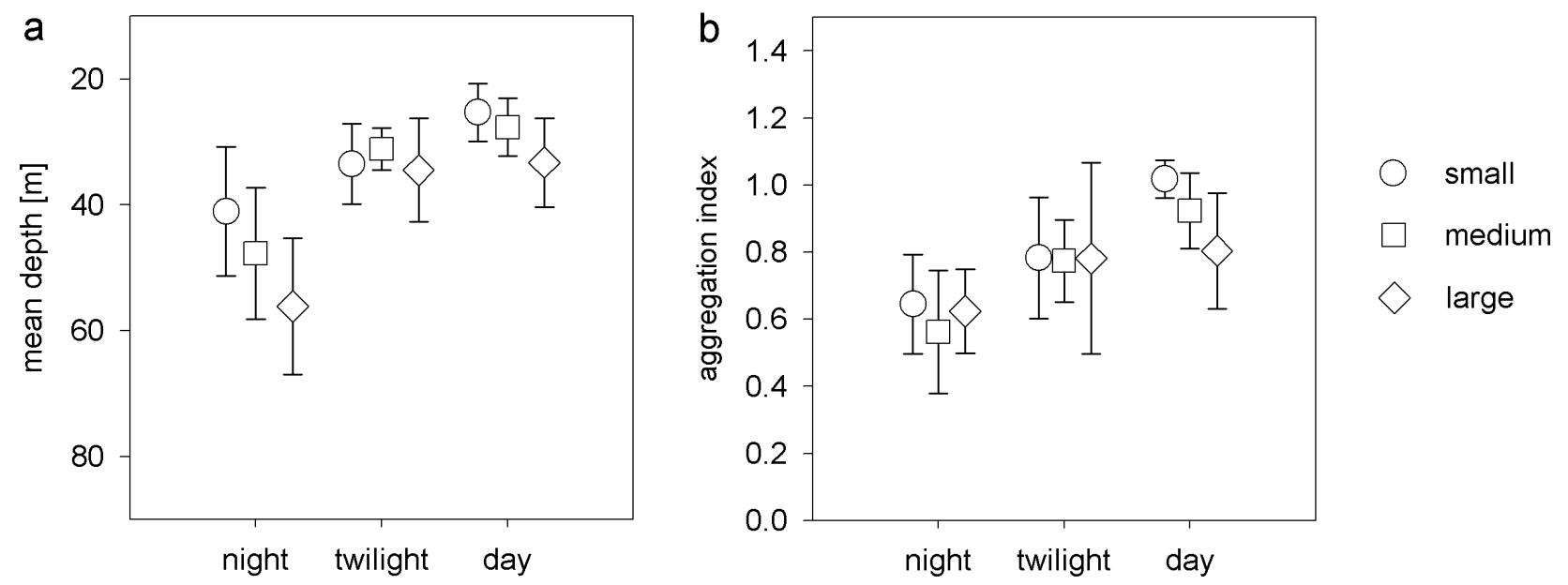

FIG. 5. - Mean depth (a) and aggregation index (b) \pm SD for different size groups of herring larvae at different time periods during the day. 
TABLE 1. - Spearman rank correlation coefficients $\left(r_{s}\right)$ for the relationship between mean depth of larval occurrence and solar radiation or wind speed for different size groups of herring larvae. Asterisks mark significant correlations. Significance levels have been adjusted with a sequential Bonferroni technique.

\begin{tabular}{lllll}
\hline & Small & Medium & Large & All larvae \\
\hline Solar radiaton & $-0.57^{*}$ & $-0.67^{*}$ & $-0.77^{*}$ & $-0.70^{*}$ \\
Wind speed & -0.14 & -0.14 & -0.06 & -0.12 \\
\hline
\end{tabular}

The abundance of herring larvae and their prey organisms per 1-m depth stratum revealed no significant correlation in the analysed IPR sequences (copepods: $r_{s}=0.06, p=0.78$; pteropods: $r_{s}=0.19, p=0.33$ ). The only significant correlation that could be detected on this fine scale occurred between the abundance of copepods and chaetognaths $\left(\mathrm{r}_{\mathrm{s}}=0.48 ; \mathrm{p}<0.05\right)$.

For some IPR tapes all herring larvae and their potential predators were counted. The fine-scale results for one complete IPR haul during daylight are displayed exemplarily in Figure 7. Only a few ctenophores were recorded between 15 and $50 \mathrm{~m}$ depth (Fig. 7a). Most herring larvae were detected between 20 and $60 \mathrm{~m}$, confirming the results obtained by multinet casts conducted during daylight. Compared with other organisms, chaetognaths were detected in higher numbers throughout the water column, with highest concentrations below $70 \mathrm{~m}$ (Fig. 7c). In contrast to the herring larvae, no diel vertical migration
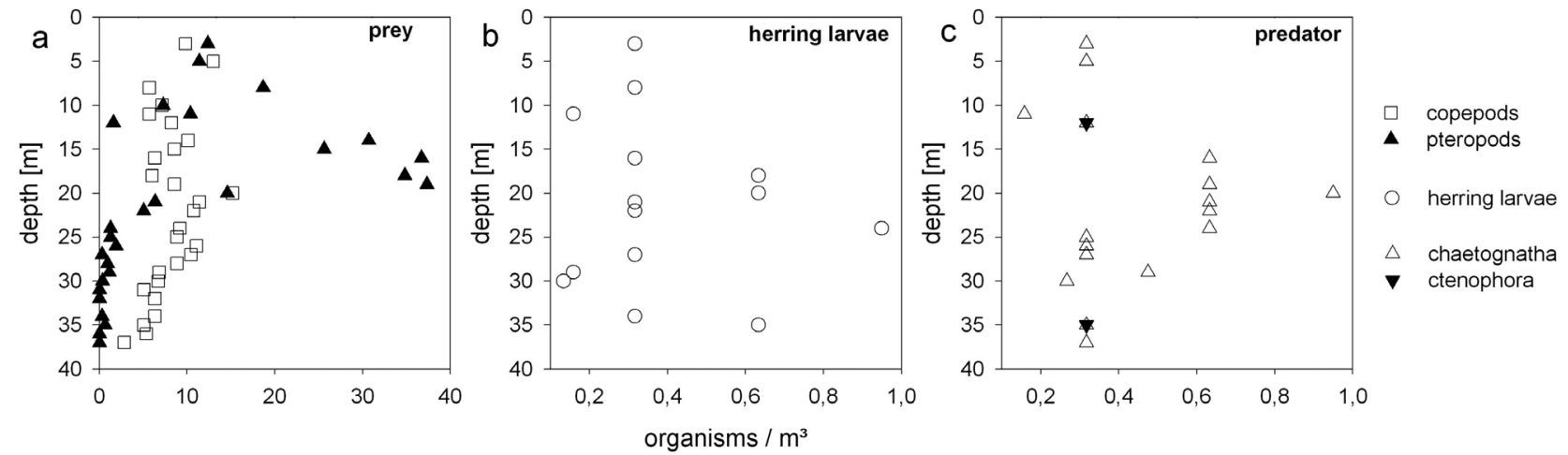

FIG. 6. - In-situ registration of small scale distribution of herring larvae and their possible prey organisms and predators for the upper $40 \mathrm{~m}$ of the water column recorded with the IPR.
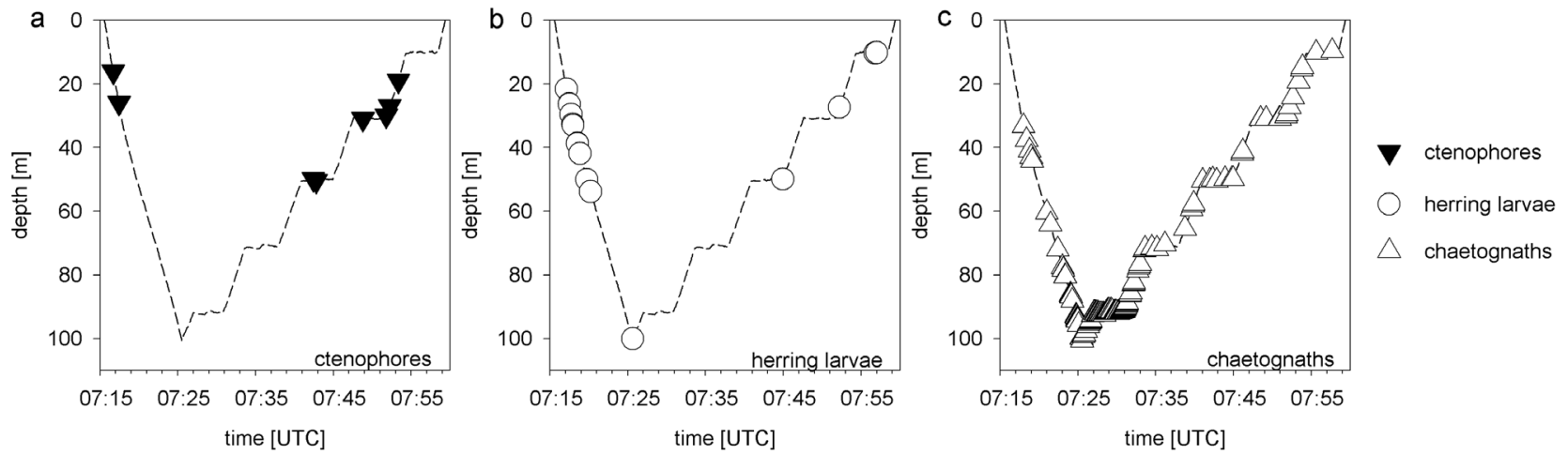

FIG. 7. - In-situ registration with the IPR of small scale vertical distribution of herring larvae and their potential predators. Each symbol represents one organism. Dashed line indicates the track of the IPR through the water column.

TABLE 2. - Results of two way ANOVAs conducted to test for differences in larval mean depth and aggregation index for different larval size groups. Asterisks mark significant p-values.

\begin{tabular}{llcccc}
\hline & & & & \\
& Source & DF & Sum of \\
& & & F Ratio & p-value \\
\hline mean depth & daytime & 2 & 6059.6766 & 40.867 & $<0.0001^{*}$ \\
& size & 2 & 682.0022 & 4.5995 & $0.0137 *$ \\
aggregation index & daytime*size & 4 & 341.1045 & 1.1502 & 0.3413 \\
& daytime & 2 & 1.3619 & 28.807 & $<0.0001 *$ \\
& size & 2 & 0.0972 & 2.0551 & 0.2512 \\
& daytime*size & 4 & 0.1301 & 1.3761 & 0.2523 \\
\hline
\end{tabular}




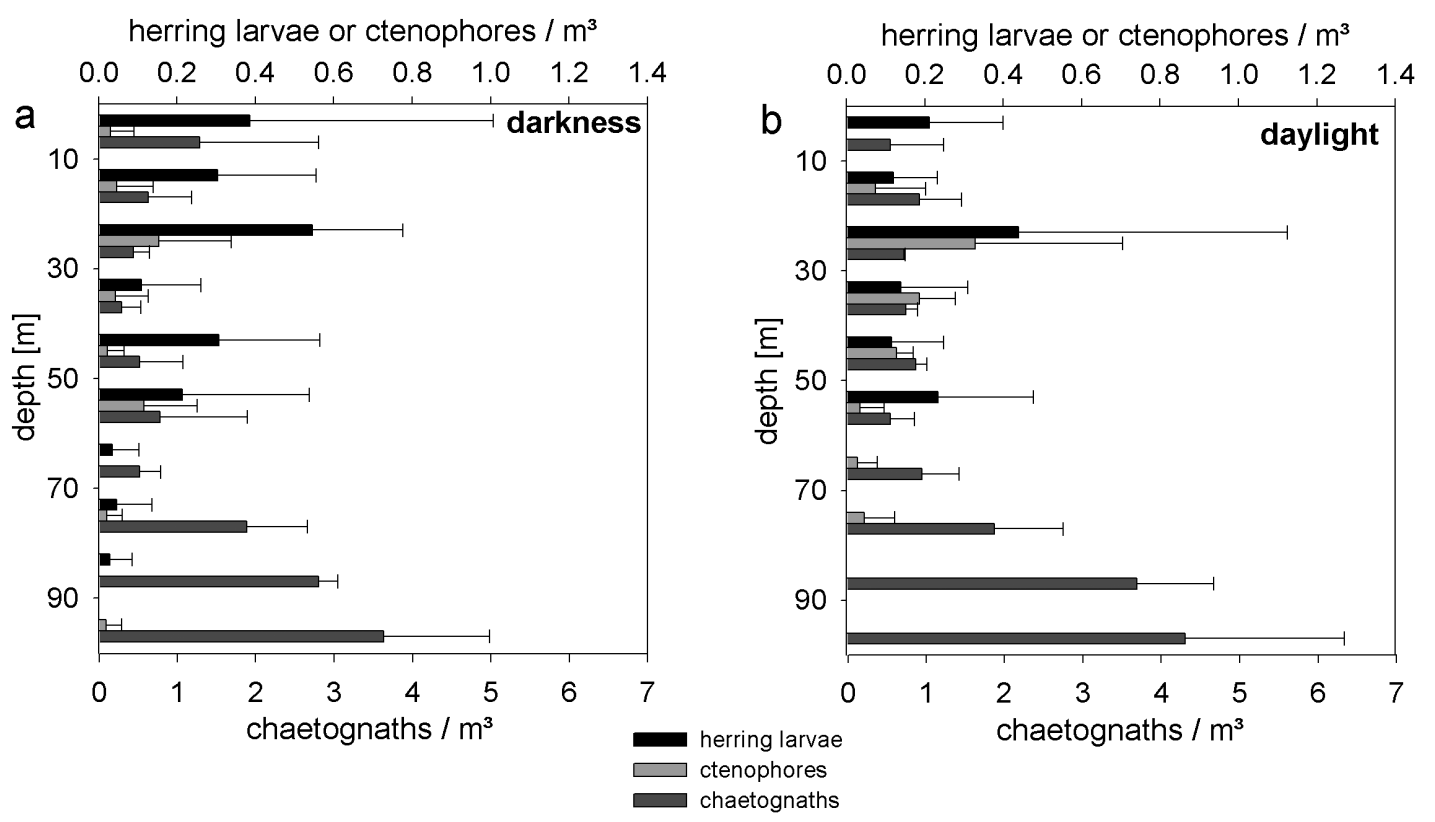

FIG. 8. - Vertical distribution of herring larvae, chaetognaths and ctenophores during darkness (a) and daylight (b), revealed with the IPR. Continuous recordings have been averaged to $10 \mathrm{~m}$ depth intervals. The upper $\mathrm{x}$-axis refers to herring larvae and ctenophores, the lower $\mathrm{x}$-axis refers to chaetognaths.

pattern was observed for chaetognaths, which seem to be concentrated in deeper water layers the whole day (Fig. 8). Ctenophores were recorded only sporadically in the depth range from the surface to $60 \mathrm{~m}$ and no conclusion regarding a possible diel migration could be made in this case (Fig. 8).

\section{DISCUSSION}

With the temporal and vertical resolution of the present study, it was possible to show the diel migration pattern of herring larvae over a period of 4 days. The results show a distinct vertical migration to upper water layers during the day and a more homogenous distribution during the night. The migration pattern was found to be more pronounced for large larvae than for small larvae in our study. In the literature, different and also contradictory observations on the diel vertical distribution pattern of herring larvae can be found. The results of our study compare well with those of Heath et al. (1991), who also observed an increasing vertical range of diel migration with increasing herring larva length. Similar results were also described by Munk et al. (1989), who related their findings to larval feeding behaviour in respect to light intensity and prey availability.

Herring larvae are affected by their ambient hydrographic conditions. The habitat of the autumn spawning herring larvae in the Shetland/Orkney area during the study period in 1999 was characterised by a mixed water column. Consequently, it was not possible to test for a correlation between ambient hydrographic conditions and the vertical distribution of herring larvae, due to a lack of contrast in the hydrographic parameters in the well-mixed water layer. The temperature gradient from the surface to the bottom did not exceed $1.5^{\circ} \mathrm{C}$. After Seliverstov (1974), this range does not affect the vertical migration of herring larvae. The same is considered for the minor changes in salinity from surface to bottom. Heath et al. (1988) showed that herring larvae are mainly located in the mixed layer when the water column is stratified. However, in a totally mixed situation, herring larvae can be found throughout the water column. The latter was also observed in the present study for the hauls conducted during the night for herring larvae $<16$ $\mathrm{mm}$, but not for hauls conducted during daylight and not for larger larvae, which showed a pronounced difference in depth preference between day and night.

It is also possible that the vertical distribution of herring larvae can be affected by tidal currents (Stephenson and Power, 1988). This was not investigated in detail in the present study. The position of the permanent station is located in an area with varying wind-driven currents at the surface. The tidal currents in this area are influenced by the Fair Isle Current (Dooley, 1983). However, as the observed vertical 
migration pattern follows a clear one-day rhythm, there is no evidence for an impact of tidal currents, which in general follow a half-day rhythm.

As herring larvae are visual predators, light is a limiting factor for their feeding behaviour and it has been shown that feeding does not occur at low light intensities (Blaxter, 1962). Consequently the best correlation was found between solar radiation and vertical distribution of herring larvae. In a study by Munk et al. (1989), herring larvae were observed to migrate into depth zones where they can prey successfully due to sufficient light and prey availability. There is some evidence from the IPR results (e.g. Fig. 8) that higher numbers of herring larvae do occur in the depth range between 15 to $25 \mathrm{~m}$, where also the highest numbers of pteropods and copepods were found. Thus, the vertical migration of herring larvae to upper water layers during the day observed in the present study could be explained by a similar behaviour regarding light intensity and prey abundance. The size dependency of the diel migration pattern, which has been described in the literature (Wood, 1971; Schnack, 1972; Munk, 1989; Heath et al., 1991), was also apparent in our investigations. Small larvae $<10 \mathrm{~mm}$ already showed a deeper position in the water layer during the night than during the day. This behaviour was even more pronounced for larvae $\geq 16 \mathrm{~mm}$. The difference in the vertical distribution of different size groups of herring larvae during the day could be explained by differences in their food preference. In the course of ontogenetic development, the food preference of herring larvae shifts from small copepod eggs and nauplii to larger copepods (Lough and Cohen, 1983). There is evidence from a previous study that the distribution of prey organisms is responsible for the size-dependent vertical distribution pattern (Munk et al., 1989). The difference in the distribution pattern between small and large larvae during the night could also be due to size-dependent sinking speeds of herring larvae (Blaxter and Ehrlich, 1974). When light intensity falls below a critical value at dusk, herring larvae are not able to prey any longer on their food organisms. Hence, the swimming intensity of herring larvae is reduced (Blaxter, 1968; Batty, 1987). The occurrence of larger herring larvae in deeper water layers during the night can therefore be explained by the increasing sinking speed with larvae size (Blaxter and Ehrlich, 1974). If one assumes that the herring larvae migrate actively in the vertical plane, a size dependency is also reasonable due to the better swimming ability of larger larvae.
The yolk-sac stages of herring larvae are not dependent on moving towards water layers with sufficient prey densities during day time. These early larvae stages are more vulnerable to planktonic predators due to their small body size, lower swimming speed and lower escape capability. The best survival strategy of these larvae would therefore be to avoid water layers with high predator densities. It is well documented that the yolk-sac stages show a phototactic response and are capable of swimming upwards in the water column (Blaxter, 1968). The results of the Ichthyoplankton Recorder casts show that high abundances of chaetognaths are found in the deeper water layers throughout the day, whereas small larvae were rarely found at these depths. However, it remains difficult to determine whether the migration behaviour of small larvae is due to active predator avoidance during the day and sinking during the night caused by reduced swimming activity. It would also be possible that abundance of small herring larvae in deeper water layers is low because they have fallen prey to their abundant predators (Fortier and Harris, 1989).

Many factors can have an impact on the vertical migration behaviour, and it strongly depends on the sampling site with its local hydrographic conditions, current system and water depth (Heath et al., 1991). Further, the many studies that already exist on the vertical behaviour have been conducted with different gears, different sampling strategies, and sometimes the duration of sampling was not sufficient to reveal the complete migration pattern. Therefore, it will remain difficult to assess the importance of each mechanism driving the vertical migration behaviour of herring larvae. The vertical distribution pattern we have described in the present study is very clear for the observed time period and this certain area. Thus, our results can be valuable for individualbased modelling of the fate of larval herring populations originating from the Shetland/Orkney spawning area. However, it cannot be ruled out that, for instance, stronger turbulences caused by strong wind will change this pattern.

The results from the IPR analysis regarding the fine-scale distribution of herring larvae and their potential food organisms revealed no clear relationship. It might be that the spatial resolution on a metre scale is too small to detect significant correlations with a restricted number of samples, as the variability on this scale is rather large. Binning the results into broader depth intervals could circumvent this problem. However, our analysis was not improved 
by averaging the results for $3 \mathrm{~m}$ depth intervals. For broader depth intervals our observations were too few in number. At least the results show that during the day herring larvae do occur in the same depth range as their potential prey. It was also possible to describe the vertical distribution of chaetognaths and ctenophores in relation to herring larvae with the IPR system. As the IPR records continuously, it would be a useful tool for detecting and quantifying horizontal and vertical patchiness, provided an automated image analysis allowing a suitably large amount of video frames to be handled can be developed.

\section{ACKNOWLEDGEMENTS}

We thank all those involved in sampling the material, especially the crew of RV Alkor and RV Heincke. For technical support we thank D. Jarosch, $\mathrm{S}$. Mees and R. Lüthje. We are also grateful to two anonymous referees for helpful suggestions on improving the manuscript.

\section{REFERENCES}

Bartsch, J., K. Brander, M. Heath, P. Munk, K. Richardson and E. Svendsen. - 1989. Modelling the advection of herring larvae in the North Sea. Nature, 340: 632-636.

Batty, R.S. - 1987. Effect of light intensity on activity and foodsearching of larval herring Clupea harengus: a laboratory study. Mar. Biol., 94: 323-327.

Blaxter, J.H.S. - 1962. The feeding of herring larvae and their ecology in relation to feeding. Calif. Coop. Oceanic Fish. Invest. Rep., 10: 79-88.

Blaxter, J.H.S. and K.F. Ehrlich. - 1974. Changes in behaviour during starvation of herring and plaice larvae. In J.H.S. Blaxter (ed.), The Early Life History of Fish, pp. 575-588. Springer, Berlin.

Blaxter, J.H.S. - 1968. Visual thresholds and spectral sensitivity of herring larvae. J. exp. Biol., 48. 39-53.

Brewer, G.D., G.S. Kleppel and M. Dempsey. - 1984. Apparent predation on ichthyoplankton by zooplankton and fishes in nearshore waters of southern California. Mar. Biol., 80: 17-28.

Cohen, R.E. and R.G. Lough. - 1983. Prey field of larval herring Clupea harengus on a continental shelf spawning area. Mar. Ecol. Prog. Ser., 10: 211-222.

Corten, A. - 1986. On the causes of the recruitment failure of herring in the central and northern North Sea in the years 19721978. J. Cons. Int. Explor. Mer., 42: 281-294.

Dooley, H.D. - 1983. Seasonal variability in the position and strength of the Fair Isle Current. In J. Suendermann and W. Lenz (eds.), Proceed. Symp. North Sea dynamics. Hamburg 1981: 108-119.

Fortier, L. and R.P. Harris. - 1989. Optimal foraging and densitydependent competition in marine fish larvae. Mar. Ecol. Prog. Ser., 51: 19-33.

Fortier, L. and W.C. Leggett. - 1983. Vertical migrations and transport of larval fish in a partially mixed estuary. Can. J. Fish. Aquat. Sci., 40: 1543-1555.
Fox, C.J., R. Harrop and A. Wimpenny. - 1999: Feeding ecology of herring (Clupea harengus) larvae in the turbid Blackwater Estuary. Mar. Biol., 134: 353-365.

Grainger, R.J.R. - 1980. The distribution and abundance of early herring (Clupea harengus L.) larvae in Galway Bay in relation to oceanographic conditions. Proc. R. Ir. Acad. 80B: 47-60.

Gröger, J., D. Schnack and N. Rohlf. - 2001: Optimisation of survey design and calculation procedure for the International Herring Larvae Survey in the North Sea. Arch. Fish. Mar. Res., 49 (2): 103-116.

Heath, M.R., K. Brander, P. Munk and P. Rankine. - 1991. Vertical distribution of autumn spawned larval herring (Clupea harengus L.) in the North Sea. Cont. Shelf Res., 11(12): 1425-1452.

Heath, M.R., E.W. Henderson and D.L. Baird. - 1988. The vertical distribution of herring larvae in relation to mixing and illumination. Mar. Ecol. Prog. Ser., 47: 221-228.

Henderson, P.A. - 1987. The vertical and transverse distribution of larval herring in the River Blackwater estuary, Essex. J. Fish. Biol., 31: 281-290.

Hinckley, S., A.J. Hermann, K.L. Mier and B.A. Megrey. - 2001. Importance of spawning location and timing to successful transport to nursery areas: a simulation study of Gulf of Alaska walleye Pollack. ICES J. Mar. Sci., 58: 1042-1052.

Hinrichsen, H.H., G. Kraus, R. Voss, D. Stepputtis and H. Baumann. -2005 . The general distribution pattern and mixing probability of Baltic sprat juvenile populations. J. Mar. Sys., 58: 52-66.

Holm, S. - 1979. A simple sequentially rejective multiple test procedure. Scand. J. Stat., 6: 65-70.

Houde, E.D. and K.M. Bailey. - 1989. Predation on eggs and larvae of marine fishes and the recruitment problem. Adv. Mar. Biol., 25: S. 1-83.

ICES. - 2008. Report of the Planning Group for Herring Surveys (PGHERS), 22-25 January 2008, IJmuiden, the Netherlands. ICES CM 2008/LRC:01. 1-257.

Lenz, J., D. Schnack, D. Petersen, J. Kreikemeier, B. Hermann, S. Mees and K. Wieland. - 1995. The Ichthyoplankton Recorder: a video recording system for in-situ studies of small-scale plankton distribution patterns. ICES J. mar. Sci., 52: 409-417.

Munk, P. - 1992. Foraging behaviour and prey size spectra of larval herring Clupea harengus. Mar. Ecol. Prog. Ser., 80(2-3): $149-158$.

Munk, P., T. Kiørboe and V. Christensen. - 1989. Vertical migration of herring, Clupea harengus, larvae in relation to light and prey distribution. Environm. Biol. Fish., 26: 87-96.

Purcell, J.E. - 1985. Predation on fish eggs and larvae by pelagic cnidarians and ctenophores. Bul. Mar. Sci., 37: 739-755

Rasband, W.S. - 1997-2008 ImageJ, U.S. National Institutes of Health, Bethesda, Maryland, USA, http://rsb.info.nih.gov/ij/

Rice, R. - 1989. Analyzing tables of statistical tests. Evolution, 43(1): 223-225.

Saville, A. - 1978. Some comments on herring larval distribution and abundance in the North Sea. Rapp. P.-v. Réun. Cons. Int. Explor. Mer., 172: 172-174.

Schnack, D. - 1972. Nahrungsökologische Untersuchungen an Heringslarven. Ber. Dt. Wiss. Komm. Meeresforschung., 22(3): 273-343.

Seliverstov, A.S. - 1974. Vertical migrations of larvae of AtlantoScandian herring (Clupea harengus L.). In: J.H.S. Blaxter (ed.), The Early Life History of Fish, pp. 253-261. Springer, Berlin.

Sjøblom, V. and R. Parmanne. - 1978. The vertical distribution of Baltic herring larvae (Clupea harengus) in the Gulf of Finland. Finnish Fish. Res., 2: 5-18.

Stephenson, R.L. and M.J. Power. - 1988. Semidiel vertical movements in Atlantic herring Clupea harengus larvae: a mechanism for larval retention? Mar. Ecol. Prog. Ser., 50: 3-11.

Wood, J.R. - 1971. Some observations on the vertical distribution of herring larvae. Rapp. P.-v. Réun. Cons. Int. Explor. Mer., 160: 60-64.

Received November 15, 2008. Accepted June 25, 2009.

Published online October 5, 2009. 